\title{
Review Article \\ Role for Tetrahydrobiopterin in the Fetoplacental Endothelial Dysfunction in Maternal Supraphysiological Hypercholesterolemia
}

\author{
Andrea Leiva, ${ }^{1}$ Bárbara Fuenzalida, ${ }^{1}$ Francisco Westermeier, ${ }^{2,3}$ \\ Fernando Toledo, 4 Carlos Salomón, 5 Jaime Gutiérrez,, ${ }^{1,6}$ Carlos Sanhueza, 1 \\ Fabián Pardo, ${ }^{1}$ and Luis Sobrevia ${ }^{1,5,7}$ \\ ${ }^{1}$ Cellular and Molecular Physiology Laboratory (CMPL), Division of Obstetrics and Gynaecology, School of Medicine, \\ Faculty of Medicine, Pontificia Universidad Católica de Chile, 8330024 Santiago, Chile \\ ${ }^{2}$ Advanced Center for Chronic Diseases (ACCDiS), Faculty of Chemical \& Pharmaceutical Sciences and Faculty of Medicine, \\ Universidad de Chile, 8380492 Santiago, Chile \\ ${ }^{3}$ Faculty of Science, Universidad San Sebastián, 7510157 Santiago, Chile \\ ${ }^{4}$ Department of Basic Sciences, Faculty of Sciences, Universidad del Bío-Bío, 3780000 Chillán, Chile \\ ${ }^{5}$ University of Queensland Centre for Clinical Research (UQCCR), Faculty of Medicine and Biomedical Sciences, \\ University of Queensland, Herston, QLD 4029, Australia \\ ${ }^{6}$ Cellular Signaling and Differentiation Laboratory (CSDL), Health Sciences Faculty, Universidad San Sebastian, \\ 7510157 Santiago, Chile \\ ${ }^{7}$ Department of Physiology, Faculty of Pharmacy, Universidad de Sevilla, 41012 Seville, Spain
}

Correspondence should be addressed to Andrea Leiva; aaleiva@uc.cl and Luis Sobrevia; sobrevia@me.com

Received 3 July 2015; Accepted 23 August 2015

Academic Editor: Joern Steinert

Copyright (C) 2016 Andrea Leiva et al. This is an open access article distributed under the Creative Commons Attribution License, which permits unrestricted use, distribution, and reproduction in any medium, provided the original work is properly cited.

Maternal physiological hypercholesterolemia occurs during pregnancy, ensuring normal fetal development. In some cases, the maternal plasma cholesterol level increases to above this physiological range, leading to maternal supraphysiological hypercholesterolemia (MSPH). This condition results in endothelial dysfunction and atherosclerosis in the fetal and placental vasculature. The fetal and placental endothelial dysfunction is related to alterations in the L-arginine/nitric oxide (NO) pathway and the arginase/urea pathway and results in reduced NO production. The level of tetrahydrobiopterin $\left(\mathrm{BH}_{4}\right)$, a cofactor for endothelial NO synthase (eNOS), is reduced in nonpregnant women who have hypercholesterolemia, which favors the generation of the superoxide anion rather than NO (from eNOS), causing endothelial dysfunction. However, it is unknown whether MSPH is associated with changes in the level or metabolism of $\mathrm{BH}_{4}$; as a result, eNOS function is not well understood. This review summarizes the available information on the potential link between $\mathrm{MSPH}$ and $\mathrm{BH}_{4}$ in causing human fetoplacental vascular endothelial dysfunction, which may be crucial for understanding the deleterious effects of MSPH on fetal growth and development.

\section{Introduction}

Hypercholesterolemia is considered one of the most important risk factors for the development of cardiovascular disease (Adult Treatment Panel ATP III) [1, 2]. Pregnancy is a physiological process that can involve the development of maternal pathologies, such as preeclampsia, gestational diabetes mellitus (GDM), and metabolic disorders, including maternal pregestational obesity, supraphysiological gestational weight gain (spGWG) [3, 4], and hypercholesterolemia $[5,6]$. These alterations may compromise the health of the mother and/or the fetus [5-7]. In normal pregnancies, the mother exhibits a physiological (i.e., normal) increase (30-50\%) in the plasma total cholesterol (TCh) level in a process that is referred to as maternal physiological hypercholesterolemia (MPH) $[5,6,8]$. However, in some cases, for mostly unknown 
reasons, the TCh level is elevated far beyond the physiological range, which is referred to as maternal supraphysiological hypercholesterolemia (MSPH) [5, 6, 9]. Although studies have shown the potential adverse effects of MSPH on the early development of atherosclerosis $[10,11]$ and endothelial dysfunction in the fetoplacental vasculature $[5,6]$, the global prevalence of MSPH remains unknown [12].

Endothelial cells synthetize nitric oxide (NO), a potent vasodilator that is generated by NO synthases (NOS; i.e., the L-arginine/NO pathway), following the oxidation of Larginine in a process that depends on the bioactivity of several cofactors, including tetrahydrobiopterin $\left(\mathrm{BH}_{4}\right)[13-$ 15]. In pregnant women with MSPH, the umbilical vein dilation and endothelial NOS (eNOS) activity are reduced, and arginase (ARG) activity is increased compared with $\mathrm{MPH}[5,6]$. Remarkably, ARG inhibition results in a partial restoration of human umbilical vein dilation, suggesting that other factors play a role in this phenomenon. In nonpregnant women, hypercholesterolemia reduces the NO bioavailability by mechanisms that include a reduction in $\mathrm{BH}_{4}$ levels [16]. Reduced activity and/or level of $\mathrm{BH}_{4}$ favor(s) the generation of a superoxide anion $\left(\mathrm{O}_{2}{ }^{--}\right)$instead of $\mathrm{NO}$, resulting in endothelial dysfunction $[14,17,18]$. Altogether, this indicates that elevated plasma TCh levels may result in reduced NO synthesis via several mechanisms, leading to endothelial dysfunction. The potential effect of $\mathrm{MSPH}$ on $\mathrm{BH}_{4}$ availability and regulation of the biosynthesis of this cofactor, as well as its consequences in the modulation of fetal endothelial function, are unknown $[5,6]$. This review summarizes the findings regarding a potential link between $\mathrm{MSPH}$ and $\mathrm{BH}_{4}$ and human fetoplacental vascular endothelial dysfunction.

\section{Hypercholesterolemia}

In nonpregnant women, hypercholesterolemia is mainly related to genetic mutations involving genes that are related to cholesterol traffic, such as lipoprotein receptors and cholesterol transporters, metabolic disorders, and an imbalanced diet $[2,19]$. According to the Third Report of the National Cholesterol Education Program (NCEP) Expert Panel on Detection, Evaluation, and Treatment of High Blood Cholesterol in Adults (Adult Treatment Panel III), this condition is the main risk factor for the development of cardiovascular disease (CVD) [1, 2]. Therefore, the proper management of plasma cholesterol levels can reduce the risk of developing CVD [20]. For this reason, the clinical cut-off point for normal blood TCh in nonpregnant women is rigorously controlled and suggested to be $<200 \mathrm{mg} / \mathrm{dL}$ [1].

A higher risk of hypercholesterolemia-associated CVD also results from a reduced blood level of high-density lipoprotein cholesterol (HDL, i.e., $<40 \mathrm{mg} / \mathrm{dL}$ ) and/or an increased blood level of low-density lipoprotein cholesterol (LDL, i.e., $>100 \mathrm{mg} / \mathrm{dL}$ ); the latter depends on the global cardiovascular risk, as recently recommended in the Guideline on the Treatment of Blood Cholesterol to Reduce Atherosclerotic Cardiovascular Risk in Adults from the American Heart Association [21]. Although CVD is normally diagnosed in adults, some studies indicate that endothelial dysfunction (i.e., an initial phenomenon in the development of atherosclerosis) and early atherosclerotic lesions (i.e., fatty streaks) begin during intrauterine life, in fetal vessels, as a consequence of increased levels of maternal cholesterol $[5,6,10]$. This indicates the relevance of monitoring the potential adverse effects of maternal cholesterolemia during pregnancy on the fetal vasculature [22]. This is even more important because the current global prevalence for a high plasma concentration of TCh $(>200 \mathrm{mg} / \mathrm{dL})$ in nonpregnant women is $\sim 40 \%$ [23]. It is conceivable that a significant number of pregnant women will have increased plasma levels of cholesterol, exposing them to the inherent consequences of this condition as well as the associated fetal vascular alterations [12].

Hypercholesterolemia during Pregnancy. Pregnancy is a physiological condition that is characterized by progressive weeks of gestation-dependent increases (increasing 40-50\%) in the maternal blood level of cholesterol and triglycerides [24, 25]. $\mathrm{MPH}$ is considered an adaptive response of the mother to satisfy the high cholesterol demand of the growing fetus for membrane and hormone synthesis [26]. Unfortunately, there are no established clinical reference values for the total and lipoprotein cholesterol levels during pregnancy in the global population, including the pregnant Chilean population $[5$, $6,8]$. A summary of the literature on the TCh, lipoprotein cholesterol, and triglyceride concentrations per trimester of pregnancy for different populations is shown in Table 1. Based on the literature, the estimated mean values for TCh are 179, 226 , and $257 \mathrm{mg} / \mathrm{dL}$ for the 1st (1-13 weeks of pregnancy), 2nd (14-28 weeks of pregnancy), and 3rd (28-40 weeks of pregnancy) trimesters of pregnancy, respectively. For HDL and LDL, the mean values were 62 and 101, 73 and 131, and 68 and $149 \mathrm{mg} / \mathrm{dL}$ for the 1st, 2nd, and 3rd trimesters of pregnancy, respectively. MSPH has been defined by considering an atterm cut-off point for TCh of 280-300 mg/dL [5, 11, 27], and it is associated with vascular alterations at birth [5] and during childhood [28]. Additionally, increased oxidative stress in the maternal and fetal blood and placenta [27] as well as reduced expression of placental LDL receptors [29] was found in pregnancies that had maternal TCh levels that were higher than this cut-off point.

Although lipid trafficking through the placenta is restrictive and children born to mothers with MSPH have normal blood cholesterol levels [5, 31], a positive correlation between the maternal and fetal blood cholesterol in the 2nd and 3 rd trimesters of pregnancy has been established [11, 32]. Moreover, increased early atherosclerotic markers, such as fatty streaks and lipid peroxidation, were found in the aortas of human fetuses [11] as well as in 7- to 14-year-old children [12] who were born to mothers with MSPH. Furthermore, endothelial dysfunction in the human umbilical vein from pregnancies with TCh values that were higher than this cutoff point has been proposed to be associated with reduced endothelium dependent vascular relaxation, due to lower eNOS and higher ARG activity [5]. These results provide evidence for the potential effect of MSPH in the placenta, leading to adverse consequences for the fetal vasculature. Interestingly, there is limited information on the prevalence of $\mathrm{MSPH}$ in the global population, which is mainly because 
TABLE 1: Reported maternal plasma lipid concentration in pregnancy.

\begin{tabular}{|c|c|c|c|c|c|c|c|}
\hline $\begin{array}{l}\text { Studied population } \\
\text { (number of } \\
\text { pregnant women) } \\
\end{array}$ & $\begin{array}{l}\text { Trimester of } \\
\text { pregnancy }\end{array}$ & TCh & HDL & $\mathrm{LDL}$ & $\operatorname{Tg}$ & Observations & Reference \\
\hline \multirow{3}{*}{ USA (142) } & 1 & 180 & 70 & 110 & 112 & \multirow{3}{*}{$\begin{array}{l}\text { Maternal overweight and obesity } \\
\text { association with lipid } \\
\text { concentration during pregnancy }\end{array}$} & \multirow{3}{*}[37]{} \\
\hline & 2 & 230 & 80 & 137 & 162 & & \\
\hline & 3 & 260 & 76 & 162 & 212 & & \\
\hline \multirow{3}{*}{ Brazil (288) } & 1 & 186 & 54 & 108 & 97 & \multirow{3}{*}{$\begin{array}{l}\text { Maternal lipid concentration } \\
\text { during pregnancy as a risk factor } \\
\text { for GDM }\end{array}$} & \multirow{3}{*}[38]{} \\
\hline & 2 & 228 & 62 & 143 & 150 & & \\
\hline & 3 & 243 & 62 & 135 & 177 & & \\
\hline \multirow{3}{*}{ Argentina (101) } & 1 & 160 & 58 & 78 & 90 & \multirow{3}{*}{$\begin{array}{l}\text { Measurement of maternal plasma } \\
\text { lipids during pregnancy }\end{array}$} & \multirow{3}{*}[39]{} \\
\hline & 2 & 201 & 62 & 107 & 140 & & \\
\hline & 3 & 244 & 61 & 144 & 202 & & \\
\hline \multirow{3}{*}{ Chile (265) } & 1 & 178 & 60 & 102 & 108 & \multirow{3}{*}{$\begin{array}{l}\text { Maternal lipid concentration } \\
\text { association with impaired } \\
\text { endothelium dependent dilation } \\
\text { of the human umbilical vein }\end{array}$} & \multirow{3}{*}[6]{} \\
\hline & 2 & 232 & 73 & 124 & 179 & & \\
\hline & 3 & 269 & 75 & 147 & 244 & & \\
\hline \multirow{3}{*}{ Chile (74) } & 1 & - & - & - & - & \multirow{3}{*}{$\begin{array}{l}\text { Cut-off point for TCh in } \\
\text { maternal plasma from where } \\
\text { fetoplacental vascular } \\
\text { dysfunction is seen }\end{array}$} & \multirow{3}{*}[5]{} \\
\hline & 2 & - & - & - & - & & \\
\hline & 3 & 238 & 72 & 120 & 232 & & \\
\hline \multirow{3}{*}{ UK (178) } & 1 & 215 & 67 & 124 & 125 & \multirow{3}{*}{$\begin{array}{l}\text { Measurement of maternal plasma } \\
\text { lipids and apolipoproteins during } \\
\text { pregnancy }\end{array}$} & \multirow{3}{*}[40]{} \\
\hline & 2 & 252 & 81 & 126 & 180 & & \\
\hline & 3 & 281 & 69 & 159 & 252 & & \\
\hline \multirow{3}{*}{ UK (17) } & 1 & 164 & - & - & 77 & \multirow{3}{*}{$\begin{array}{l}\text { Measurement of maternal plasma } \\
\text { lipids and markers of oxidative } \\
\text { stress in normal and GDM } \\
\text { pregnancies }\end{array}$} & \multirow{3}{*}[41]{} \\
\hline & 2 & 212 & - & - & 133 & & \\
\hline & 3 & 261 & - & - & 233 & & \\
\hline & 1 & 197 & 65 & 104 & - & & \\
\hline Ireland (222) & 2 & 224 & 75 & 128 & - & Reference values for maternal & {$[42]$} \\
\hline & 3 & 278 & 68 & 147 & - & & \\
\hline & 1 & 178 & 68 & 97 & 93 & & \\
\hline Italy (22) & 2 & 247 & 73 & 153 & 155 & Measurement of maternal plasma & {$[43]$} \\
\hline & 3 & 282 & 68 & 168 & 230 & lipids during pregnancy & \\
\hline & 1 & 182 & 69 & 104 & 99 & & \\
\hline Sweden (18) & 2 & 238 & 79 & 140 & 165 & Measurement of maternal plasma & {$[44]$} \\
\hline & 3 & 248 & 69 & 153 & 215 & & \\
\hline & 1 & 166 & - & - & 71 & Measurement of maternal plasma & \\
\hline Spain (45) & 2 & 193 & - & - & 106 & LDL oxidation in normal, GDM, & {$[45]$} \\
\hline & 3 & 228 & - & - & 150 & and obese pregnancies & \\
\hline & 1 & 170 & 68 & 89 & 60 & Maternal lipases activity and & \\
\hline Spain (25) & 2 & 234 & 82 & 136 & 117 & hormones concentrations during & {$[46]$} \\
\hline & 3 & 254 & 71 & 153 & 184 & pregnancy & \\
\hline & 1 & 190 & 75 & 97 & 85 & & \\
\hline Serbia (50) & 2 & 245 & 89 & 126 & 151 & Maternal lipid concentration & {$[47]$} \\
\hline & 3 & 267 & 79 & 144 & 219 & association with newborn size & \\
\hline & 1 & 166 & 53 & 94 & 93 & Maternal lipid concentrations & \\
\hline Turkey (801) & 2 & - & - & - & - & 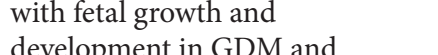 & {$[48]$} \\
\hline & 3 & 271 & 63 & 155 & 274 & $\begin{array}{l}\text { development in GDM and } \\
\text { preeclampsia }\end{array}$ & \\
\hline & 1 & 175 & 58 & 88 & 100 & Association of maternal lipid & \\
\hline Israel (3938) & 2 & 225 & 63 & 121 & 175 & concentration with preeclampsia & {$[49]$} \\
\hline & 3 & 238 & 63 & 137 & 237 & and GDM & \\
\hline & 1 & 172 & 41 & 112 & 93 & & \\
\hline Nigeria (60) & 2 & 203 & 51 & 126 & 128 & Atherosclerotic risk in pregnant & {$[50]$} \\
\hline & 3 & 232 & 63 & 136 & 171 & women & \\
\hline
\end{tabular}

Women were subjected to lipids determination at 1st trimester (0-14 weeks of gestation), 2nd trimester (14-28 weeks of gestation), or 3rd trimester (28-40 weeks of gestation) of pregnancy. TCh: total cholesterol; LDL: low-density lipoprotein; HDL: high-density lipoprotein; Tg: triglycerides. —: not reported; GDM: gestational diabetes mellitus. Values are mean in $\mathrm{mg} / \mathrm{dL}$. 
the maternal blood cholesterol level is not routinely evaluated during pregnancy. Moreover, in a group of pregnant Chilean women, the prevalence of this maternal condition was $\sim 30 \%$ $[5,6]$. As a result, a significantly higher number of pregnant women will potentially present with an adverse intrauterine condition that could result in the development of vascular alterations in the growing fetus, such as endothelial dysfunction and early atherosclerosis.

\section{Fetoplacental Endothelial Dysfunction in MSPH}

The placenta is a physical and metabolic barrier between the fetal and maternal circulations, and it is a crucial organ that supports proper fetal development [33]. Because the placenta and umbilical cord lack autonomic innervation [34], a balance between circulating vasodilators and vasoconstrictors is crucial to maintaining normal fetoplacental function $[33,35]$. Endothelial dysfunction is defined as an imbalance between vasodilator and vasoconstrictor molecules that are produced by or acting on endothelial cells [36] and that are critical for normal fetal development.

3.1. L-Arginine/NO Pathway. NO is a gas derived from the metabolism of L-arginine via the enzyme NOS, in a metabolic reaction where there is equimolar generation of L-citrulline and $\mathrm{NO}$ (as in the L-arginine/NO pathway) [7]. NOS are a group of enzymes with at least three isoforms that are encoded by different genes in mammals [57], that is, neuronal NOS (nNOS or type 1), inducible NOS (iNOS or type 2), and endothelial NOS (eNOS or type 3). eNOS is the main form that is expressed in endothelial cells [3], and reduced activity of this enzyme may result from lower expression, reduced activation, or increased inactivation $[58,59]$. eNOS activity is modulated by different agents, including the level of its cofactor $\mathrm{BH}_{4}$ and posttranslational phosphorylation/dephosphorylation. For example, phosphorylation of serine 1177 (Ser ${ }^{177}$ ) via PI3 kinase/Akt is associated with higher activity [60]; however, phosphorylation of threonine $495\left(\mathrm{Thr}^{495}\right)$ via protein kinase C (PKC) maintains a low activity of this enzyme [58, 61]. Remarkably, hypercholesterolemia is associated with reduced eNOS expression, an effect that is reversed by restoring the cholesterol levels with the use of statins, for example, [62-64]. Additionally, it has been shown that cholesterol regulates the phosphorylation of eNOS. In mice and pigs, there is a negative correlation between the TCh level and the activation-phosphorylation of $\operatorname{Ser}^{1177}[65,66]$. On the other hand, HDL also induces Ser $^{1177}$ phosphorylation of eNOS [67]. It was recently shown that, in fetoplacental macrovascular endothelial cells from pregnant women with MSPH, eNOS activity, but not its protein abundance, is reduced [5]. However, Ser ${ }^{1177}$ and Thr ${ }^{495}$ phosphorylation was reduced compared to cells from pregnant women with MPH. As a result, an altered maternal cholesterol level may modify the eNOS activity in pregnancy.

3.2. ARGs/Urea Pathway. ARGs (ARG-I and ARG-II) are a family of enzymes that compete with NOS for the substrate
L-arginine, leading to the synthesis of L-ornithine and urea [68]. Interestingly, hypercholesterolemia is associated with increased ARG activity in animal models [69, 70] and humans [71, 72]. The activity of ARGs is also increased in HUVECs from pregnancies with MSPH compared with $\mathrm{MPH}$ pregnancies [5]. Because the pharmacological blockade of ARG with $S$-(2-boronoetil)-L-cysteine (BEC) partially reverses the reduced eNOS activity observed in HUVECs in MSPH pregnancies, ARGs are likely involved in modulating eNOS activity in this cell type [4].

\section{4. $\mathrm{BH}_{4}$ Metabolism in MSPH}

4.1. $\mathrm{BH}_{4} \cdot \mathrm{BH}_{4}$ is a cofactor required for NOS activity because this molecule stabilizes the enzyme as an active dimer, allowing for optimal oxidation of L-arginine into NO [13, 15]. A reduction in the $\mathrm{BH}_{4}$ level leads to reduced eNOS activation, which is likely due to the uncoupling that results in the generation of superoxide anion $\left(\mathrm{O}_{2}{ }^{--}\right)$rather than $\mathrm{NO}$, promoting vascular oxidative stress and endothelial dysfunction [14]. In the endothelium, $\mathrm{BH}_{4}$ is synthesized by at least two metabolic pathways: de novo biosynthesis from guanosine triphosphate (GTP) and the salvage pathway from sepiapterin to $\mathrm{BH}_{2}$ and $\mathrm{BH}_{4}$ [14] (Figure 1(a)). De novo biosynthesis involves the sequential action of GTP cyclohydrolase 1 (GTPCH1), 6-piruvoil tetrahydropterin synthase (PTPS), and sepiapterin reductase (SR). The GTPCH1 step is the limiting step of the pathway, and it is highly regulated at the transcriptional, translational, and posttranslational levels [73]. For the salvage pathway, the reduction of $\mathrm{BH}_{2}$ to $\mathrm{BH}_{4}$ is the limiting step and requires the enzyme dihydrofolate reductase (DHFR) [73]. The $\mathrm{BH}_{4}$ level could be reduced by decreased synthesis and by the oxidation of $\mathrm{BH}_{4}$ to $\mathrm{BH}_{2}$ via oxygen-derived reactive species and peroxynitrite $\left(\mathrm{ONOO}^{-}\right)$, resulting in eNOS uncoupling (Figure $1(\mathrm{~b})$ ) $[13,18,74]$. The latter is a phenomenon that occurs in a variety of clinical conditions that are associated with vascular disease, including diabetes mellitus, hypertension, atherosclerosis [75-77], and hyperglycemia [18].

4.2. $\mathrm{BH}_{4}$ Metabolism in Hypercholesterolemia. Patients with hypercholesterolemia have low $\mathrm{NO}$ availability [78, 79] as well as a lower $\mathrm{BH}_{4}$ level (Table 2). Interestingly, oral or local supplementation with $\mathrm{BH}_{4}$ restores the impaired $\mathrm{NO}$-dependent vasodilation in subjects with hypercholesterolemia $[13,52,55$, 80]. The association between human hypercholesterolemia and a reduced level of GTPCH1 has not yet been addressed $[14,18]$. However, reduced eNOS activity is reversed by supplementation with the $\mathrm{BH}_{4}$ substrate sepiapterin or by GTPCH1 overexpression in mice [81-83]. As a result, this enzyme likely plays a role in hypercholesterolemia. Incubation with human LDL reduces NOS and GTPCH1 expression in rat vascular smooth muscle cells $[84,85]$. Additionally, a reduced level of GTPCH1 due to hyperglycemia in human aortic endothelial cells decreases the $\mathrm{BH}_{4}$ level and $\mathrm{NO}$ synthesis, which is reversed by GTPCH1 overexpression [86]. Interestingly, and in corroboration with these findings, there are results showing similar changes in HUVECs that 


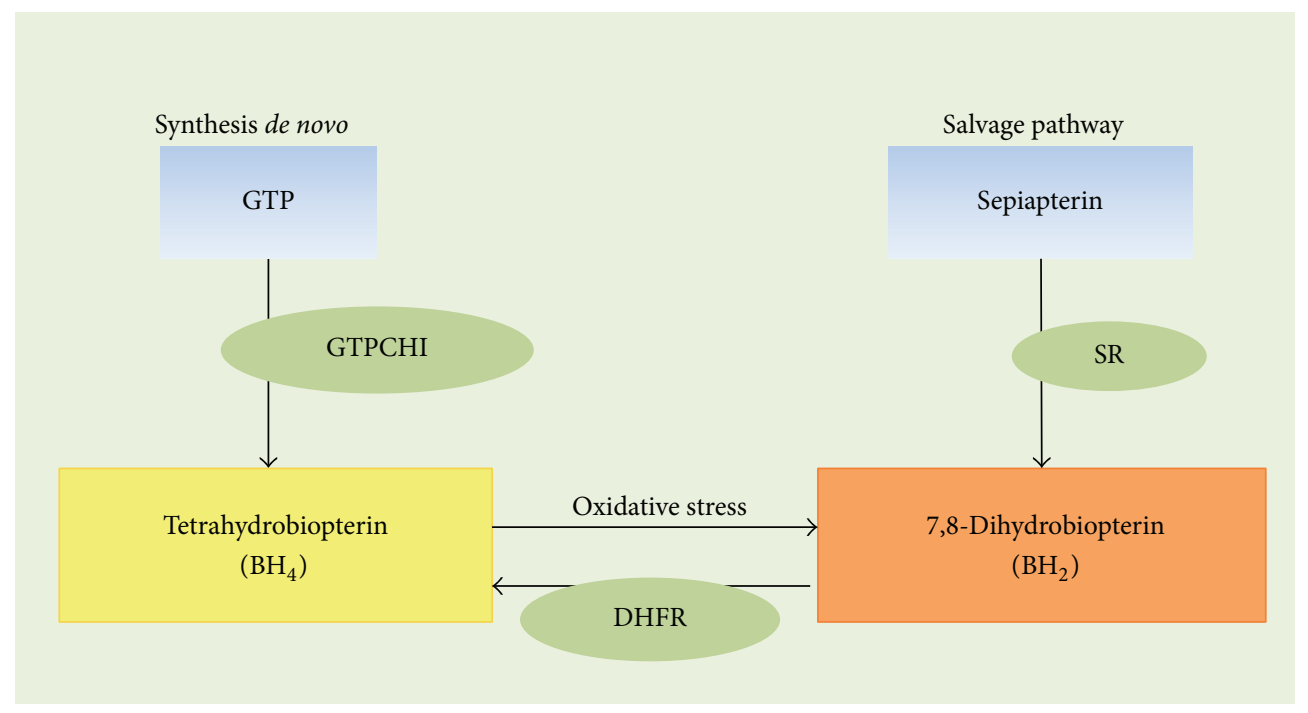

(a)

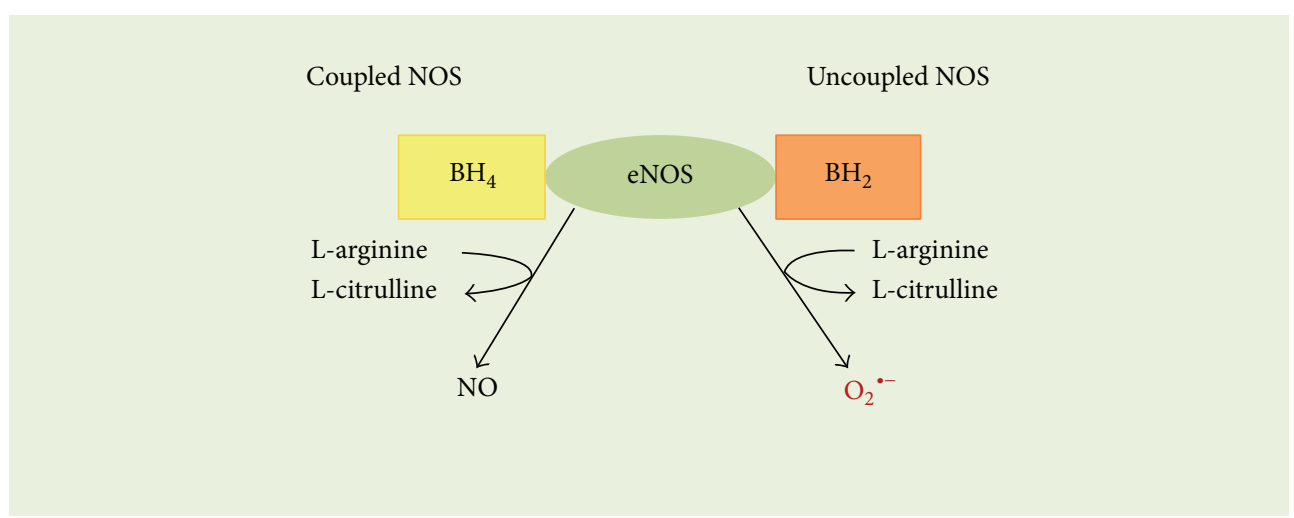

(b)

FIGURE 1: Tetrahydrobiopterin metabolism and endothelial nitric oxide synthase uncoupling. (a) The first step in the de novo synthesis of tetrahydrobiopterin $\left(\mathrm{BH}_{4}\right)$ is the rate limiting reaction involving the enzyme GTP cyclohydrolase 1 (GTPCH1), whose substrate is GTP. An alternative salvage pathway for $\mathrm{BH}_{4}$ synthesis is the reduction of 7,8-dihydrobiopterin $\left(\mathrm{BH}_{2}\right)$ to $\mathrm{BH}_{4}$ by the enzyme dihydrofolate reductase (DHFR). $\mathrm{BH}_{2}$ is generated from sepiapterin by the sepiapterin reductase enzyme (SR). Oxidative stress may be an environmental condition that promotes the oxidation of $\mathrm{BH}_{4}$ to $\mathrm{BH}_{2}$, decreasing the bioavailability of $\mathrm{BH}_{4}$. (b) Under physiological conditions, nitric oxide synthases (NOS, coupled NOS) generate nitric oxide, following the metabolism of L-arginine into L-citrulline in the presence of $\mathrm{BH}_{4}$. However, uncoupling NOS (uncoupled eNOS) with these enzymes may result in the generation of a superoxide anion $\left(\mathrm{O}_{2}{ }^{--}\right)$. This phenomenon results from a deficiency in $\mathrm{BH}_{4}$ and an increased $\mathrm{BH}_{2}$ bioavailability (from data in $[6,17,30]$ ).

were subjected to the pharmacological induction of GTPCH1 expression [87].

The potential effect of $\mathrm{MSPH}$ on $\mathrm{BH}_{4}$ availability in the regulation of the synthesis of this cofactor and its effect on the modulation of fetal endothelial function are unknown $[5,6]$. Because NO synthesis is reduced in the fetal endothelium from pregnancies with MSPH via mechanisms involving increased ARG but reduced eNOS activity, it is hypothesized that this maternal condition could also result in reduced $\mathrm{BH}_{4}$ bioavailability for NO synthesis. As a result, these potential mechanisms could explain the endothelial dysfunction and reduced vascular relaxation observed in MSPH. Preliminary results show that the $\mathrm{BH}_{4}$ level is reduced in HUVECs from
MSPH [88] (Leiva A., Sobrevia L., unpublished). However, it is unknown whether $\mathrm{BH}_{4}$ metabolism is altered in human fetoplacental endothelial cells in pregnancies with MSPH or whether restoration of the $\mathrm{BH}_{4}$ level improves the endothelial dysfunction in MSPH [4-6, 33].

\section{Concluding Remarks}

The prevalence of MSPH in the global population has not been evaluated, although it is estimated as approximately $30 \%[5,6]$. MSPH is a factor that favors the development of vascular changes in the growing fetus and, eventually, in children [12]. These vascular disorders include endothelial 
TABLE 2: Effect of hypercholesterolemia on tetrahydrobiopterin availability and endothelial function.

\begin{tabular}{|c|c|c|c|c|c|c|}
\hline Study model & Tissue or cell type & $\begin{array}{l}\text { Experimental } \\
\text { condition }\end{array}$ & $\mathrm{BH}_{4}$ level & Parameter & Effect & Reference \\
\hline \multirow{2}{*}{ Hypercholesterolemia } & \multirow{2}{*}{$\begin{array}{l}\text { Human brachial } \\
\text { artery }\end{array}$} & Basal & Reduced & $\begin{array}{l}\text { Endothelium dependent } \\
\text { vasodilation }\end{array}$ & Reduced & \multirow[t]{2}{*}{ [13] } \\
\hline & & $\mathrm{BH}_{4}$ infusion & Increased & $\begin{array}{c}\text { Endothelium dependent } \\
\text { vasodilation }\end{array}$ & Increased & \\
\hline \multirow{2}{*}{ Hypercholesterolemia } & \multirow{2}{*}{$\begin{array}{l}\text { Human coronary } \\
\text { artery }\end{array}$} & Basal & Reduced & $\begin{array}{l}\text { Coronary artery } \\
\text { diameter and flow }\end{array}$ & Reduced & \multirow[t]{2}{*}{ [51] } \\
\hline & & $\mathrm{BH}_{4}$ infusion & Increased & $\begin{array}{c}\text { Coronary artery } \\
\text { diameter and flow }\end{array}$ & Increased & \\
\hline \multirow{2}{*}{ Hypercholesterolemia } & \multirow{2}{*}{$\begin{array}{l}\text { Human brachial } \\
\text { artery }\end{array}$} & Basal & Reduced & $\begin{array}{c}\text { Endothelium dependent } \\
\text { vasodilation }\end{array}$ & Reduced & \multirow{2}{*}[52]{} \\
\hline & & $\mathrm{BH}_{4}$ supplementation & Increased & $\begin{array}{c}\text { Endothelium dependent } \\
\text { vasodilation }\end{array}$ & Increased & \\
\hline \multirow[b]{2}{*}{ Hypercholesterolemia } & \multirow{2}{*}{$\begin{array}{l}\text { Human coronary } \\
\text { microcirculation }\end{array}$} & Basal & $\mathrm{nr}$ & Myocardial blood flow & Reduced & \multirow[b]{2}{*}[53]{} \\
\hline & & $\mathrm{BH}_{4}$ infusion & $\mathrm{nr}$ & Myocardial blood flow & Increased & \\
\hline \multirow{3}{*}{ Hypercholesterolemia } & \multirow{3}{*}{ Human skin } & Basal & $\mathrm{nr}$ & $\begin{array}{l}\text { Endothelium dependent } \\
\text { vasodilation }\end{array}$ & Reduced & \multirow{3}{*}[54]{} \\
\hline & & $\mathrm{R}-\mathrm{BH}_{4}$ infusion & $\mathrm{nr}$ & $\begin{array}{l}\text { Endothelium dependent } \\
\text { vasodilation }\end{array}$ & Increased & \\
\hline & & $\mathrm{S}-\mathrm{BH}_{4}$ infusion & $\mathrm{nr}$ & $\begin{array}{c}\text { Endothelium dependent } \\
\text { vasodilation }\end{array}$ & Reduced & \\
\hline \multirow{2}{*}{ Hypercholesterolemia } & \multirow{2}{*}{ Human skin } & Basal & $\mathrm{nr}$ & $\begin{array}{c}\text { Endothelium dependent } \\
\text { vasodilation }\end{array}$ & Reduced & \multirow{2}{*}{ [55] } \\
\hline & & $\mathrm{BH}_{4}$ infusion & $\mathrm{nr}$ & $\begin{array}{c}\text { Endothelium dependent } \\
\text { vasodilation }\end{array}$ & Increased & \\
\hline \multirow{4}{*}{ Cell culture } & \multirow{4}{*}{$\begin{array}{l}\text { Human mesenteric } \\
\text { microvascular } \\
\text { endothelial cells }\end{array}$} & Incubation with & Reduced & NO generation & Reduced & \multirow{4}{*}[56]{} \\
\hline & & oxLDL & Reduced & Superoxide generation & Increased & \\
\hline & & Incubation with & Increased & NO generation & Increased & \\
\hline & & oxLDL + sepiapterin & Increased & Superoxide generation & Reduced & \\
\hline \multirow{2}{*}{ Cell culture } & \multirow{2}{*}{$\begin{array}{l}\text { Human aortic } \\
\text { endothelial cells }\end{array}$} & Incubation with LDL & Reduced & NO generation & Reduced & \multirow{2}{*}[52]{} \\
\hline & & $\begin{array}{l}\text { Incubation with LDL } \\
+\mathrm{BH}_{4}\end{array}$ & $\mathrm{nr}$ & NO generation & Increased & \\
\hline
\end{tabular}

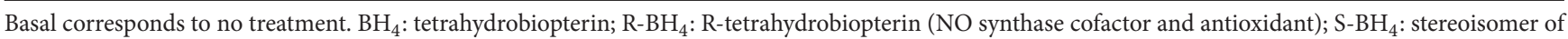
$\mathrm{BH}_{4}$ (antioxidant); oxLDL: oxidized low-density lipoprotein; LDL: low-density lipoprotein; NO: nitric oxide; nr: not reported.

dysfunction in the fetus and placenta, disrupting the equilibration between the ARG/urea and L-arginine/NO signaling pathways. However, it is unknown whether these alterations correlate with the degree of MSPH in pregnancy or the alterations in $\mathrm{BH}_{4}$ metabolism and eNOS function (Figure 2). Drugs that control the TCh plasma level in adult, nonpregnant subjects are not used during pregnancy. This condition limits our present knowledge regarding the correlation between the mother's and fetus's TCh level and the vascular function of the fetus during pregnancy. However, based on the available evidence from subjects with hypercholesterolemia, we propose that restoration of the $\mathrm{BH}_{4}$ level will improve the fetoplacental endothelial function in humans. Therefore, it is essential to focus future studies on exploring the dynamics of the $\mathrm{BH}_{4}$ metabolism in $\mathrm{MSPH}$ pregnancies and the possible contribution that restoring this cofactor could have on this maternal condition and vascular function.

\section{Conflict of Interests}

There is no conflict of interests.

\section{Authors' Contribution}

Andrea Leiva and Luis Sobrevia designed research study; Andrea Leiva, Bárbara Fuenzalida, and Carlos Salomón collected clinical data; Andrea Leiva, Bárbara Fuenzalida, Francisco Westermeier, Fernando Toledo, Jaime Gutiérrez, Carlos Sanhueza, and Fabián Pardo collected and analyzed literature 


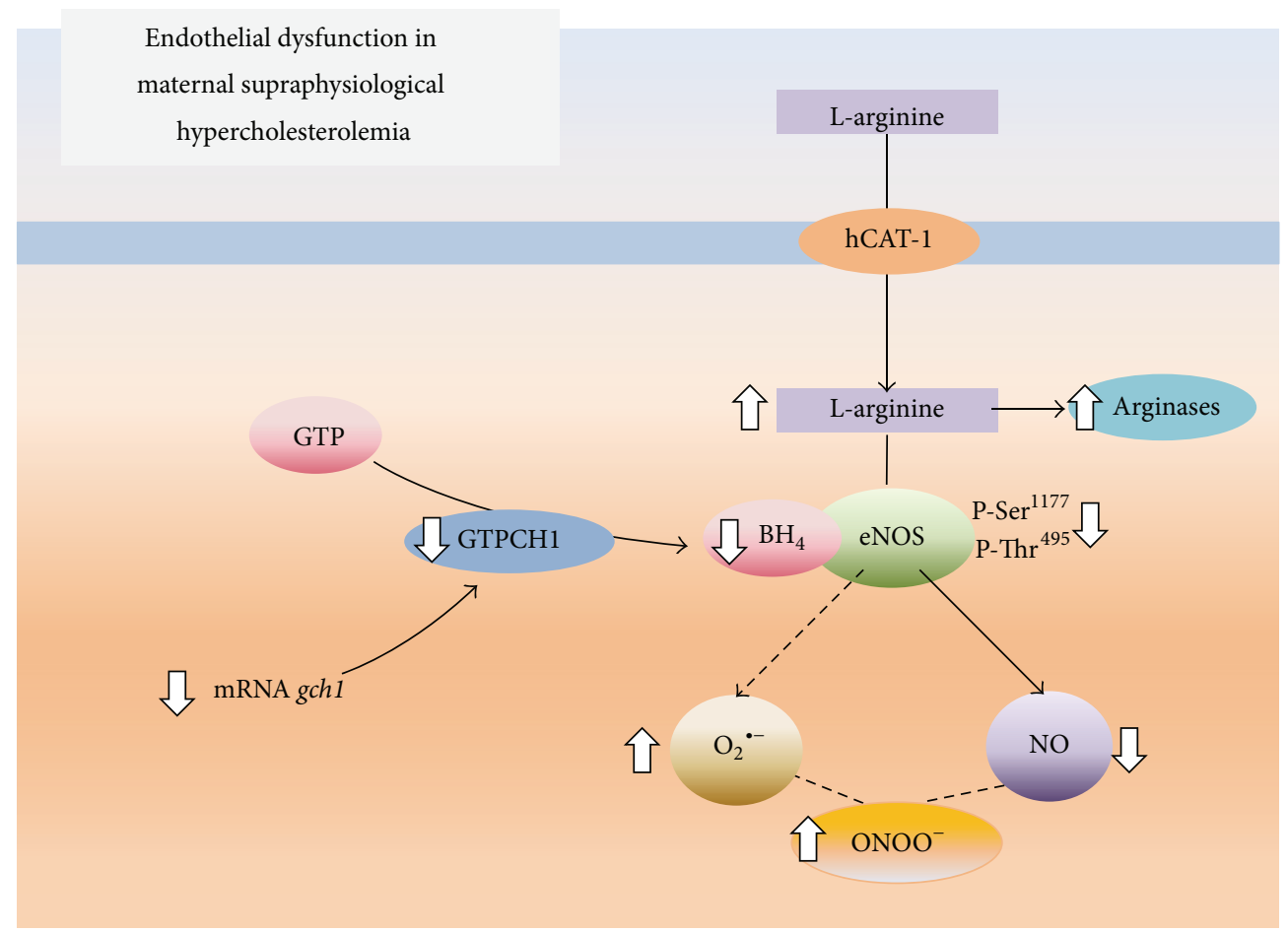

FIGURE 2: Effect of maternal supraphysiological hypercholesterolemia on the endothelial L-arginine/NO signaling pathway. In umbilical vein endothelial cells from pregnancies complicated by maternal physiological hypercholesterolemia, the amino acid L-arginine is taken up by the human cationic amino acid transporter 1 (hCAT-1) and metabolized by endothelial nitric oxide synthase (eNOS) and, to a lesser extent, arginases. This phenomenon occurs in the presence of tetrahydrobiopterin $\left(\mathrm{BH}_{4}\right)$, resulting in $\mathrm{NO}$ generation. $\mathrm{BH}_{4}$ is generated by the enzyme GTP cyclohydrolase 1 (GTPCH1), which is coded by the gch1 gene and whose substrate is GTP. In cells from pregnancies where the pregnant women had maternal supraphysiological hypercholesterolemia, hCAT-1-mediated L-arginine transport is increased ( $\Uparrow$ ), increasing the availability of this amino acid for eNOS and arginases. In this pathological condition, L-arginine is mainly used by arginases, limiting the formation of NO via eNOS. In addition, eNOS has reduced $(\Downarrow)$ activity because of the lower phosphorylation of Ser ${ }^{177}$ and the bioavailability of $\mathrm{BH}_{4}$. The reduction in the $\mathrm{BH}_{4}$ concentration results from a reduced expression of $g c h 1$, leading to eNOS uncoupling and the generation of a superoxide anion $\left(\mathrm{O}_{2}{ }^{--}\right)$. The $\mathrm{O}_{2}{ }^{--}$reacts with $\mathrm{NO}$ to form peroxynitrite (ONOO ${ }^{-}$; from data in $\left.[5-7,14]\right)$.

information; Andrea Leiva and Luis Sobrevia designed the figures; Andrea Leiva, Bárbara Fuenzalida, Fernando Toledo, and Fabián Pardo constructed the tables; Andrea Leiva, Bárbara Fuenzalida, and Luis Sobrevia wrote the paper.

\section{Acknowledgments}

The authors thank Mrs. Amparo Pacheco and Mrs. Ninoska Muñoz from CMPL, Pontificia Universidad Católica de Chile (PUC), for excellent technical and secretarial assistance, respectively. This work was supported by Fondo Nacional de Desarrollo Científico y Tecnológico (FONDECYT 1150344, 1150377, 3130583, 3140516, and 3140532), Chile.

\section{References}

[1] National Cholesterol Education Program (NCEP), “Third report of the National Cholesterol Education Program (NCEP) expert panel on detection, evaluation, and treatment of high blood cholesterol in adults (adult treatment panel III) final report," Circulation, vol. 106, no. 25, pp. 3143-3421, 2002.

[2] D. Mozaffarian, E. Benjamin, A. Go et al., "Heart disease and stroke statistics-2015 update: a report from the American Heart Association," Circulation, vol. 13, no. 4, pp. e29-e322, 2015.
[3] F. Pardo, P. Arroyo, C. Salomón et al., "Role of equilibrative adenosine transporters and adenosine receptors as modulators of the human placental endothelium in gestational diabetes mellitus," Placenta, vol. 34, no. 12, pp. 1121-1127, 2013.

[4] F. Pardo, L. Silva, R. Salsoso et al., "Fetoplacental endothelial dysfunction in maternal hypercholesterolemia and obesity in pregnancy," Physiological Mini-Reviews, vol. 7, no. 5, pp. 60-76, 2014.

[5] A. Leiva, C. D. de Medina, R. Salsoso et al., "Maternal hypercholesterolemia in pregnancy associates with umbilical vein endothelial dysfunction: role of endothelial nitric oxide synthase and arginase II," Arteriosclerosis, Thrombosis, and Vascular Biology, vol. 33, no. 10, pp. 2444-2453, 2013.

[6] A. Leiva, C. D. de Medina, E. Guzmán-Gutierrez, F. Pardo, and L. Sobrevia, "Maternal hypercholesterolemia in gestational diabetes and the association with placental endothelial dysfunction," in Gestational Diabetes-Causes, Diagnosis and Treatment, L. Sobrevia, Ed., chapter 6, pp. 103-134, InTech, Rijeka, Croatia, 1st edition, 2013.

[7] A. Leiva, F. Pardo, M. A. Ramírez, M. Farías, P. Casanello, and L. Sobrevia, "Fetoplacental vascular endothelial dysfunction as an early phenomenon in the programming of human adult diseases in subjects born from gestational diabetes mellitus or obesity in pregnancy," Experimental Diabetes Research, vol. 2011, Article ID 349286, 18 pages, 2011. 
[8] H. L. Barrett, M. D. Nitert, H. D. McIntyre, and L. K. Callaway, "Normalizing metabolism in diabetic pregnancy: is it time to target lipids?" Diabetes Care, vol. 37, no. 5, pp. 1484-1493, 2014.

[9] A. Montes, C. E. Walden, R. H. Knopp, M. Cheung, M. B. Chapman, and J. J. Albers, "Physiologic and supraphysiologic increases in lipoprotein lipids and apoproteins in late pregnancy and postpartum. Possible markers for the diagnosis of 'prelipemia,' Arteriosclerosis, vol. 4, no. 4, pp. 407-417, 1984.

[10] C. Napoli, C. K. Glass, J. L. Witztum, R. Deutsch, F. P. D'Armiento, and W. Palinski, "Influence of maternal hypercholesterolaemia during pregnancy on progression of early atherosclerotic lesions in childhood: fate of Early Lesions in Children (FELIC) study," The Lancet, vol. 354, no. 9186, pp. 1234-1241, 1999.

[11] C. Napoli, F. P. D’Armiento, F. P. Mancini et al., "Fatty streak formation occurs in human fetal aortas and is greatly enhanced by maternal hypercholesterolemia. Intimal accumulation of low density lipoprotein and its oxidation precede monocyte recruitment into early atherosclerotic lesions," The Journal of Clinical Investigation, vol. 100, no. 11, pp. 2680-2690, 1997.

[12] W. Palinski, "Effect of maternal cardiovascular conditions and risk factors on offspring cardiovascular disease," Circulation, vol. 129, no. 20, pp. 2066-2077, 2014.

[13] E. Stroes, J. Kastelein, F. Cosentino et al., “Tetrahydrobiopterin restores endothelial function in hypercholesterolemia," Journal of Clinical Investigation, vol. 99, no. 1, pp. 41-46, 1997.

[14] M. J. Crabtree and K. M. Channon, "Synthesis and recycling of tetrahydrobiopterin in endothelial function and vascular disease," Nitric Oxide, vol. 25, no. 2, pp. 81-88, 2011.

[15] H. Li and U. Förstermann, "Uncoupling of endothelial NO synthase in atherosclerosis and vascular disease," Current Opinion in Pharmacology, vol. 13, no. 2, pp. 161-167, 2013.

[16] S. Ma and C. C.-H. Ma, "Recent developments in the effects of nitric oxide-donating statins on cardiovascular disease through regulation of tetrahydrobiopterin and nitric oxide," Vascular Pharmacology, vol. 63, no. 2, pp. 63-70, 2014.

[17] M. González, E. Muñoz, P. Puebla et al., "Maternal and fetal metabolic dysfunction in pregnancy diseases associated with vascular oxidative and nitrative stress," in The Molecular Basis for the Link between Maternal Health and the Origin of Fetal Congenital Abnormalities An Overview of Association with Oxidative Stress, B. Matata and M. Elahi, Eds., pp. 98-115, Bentham Science Publishers, Oak Park, Ill, USA, 1st edition, 2011.

[18] M. González, S. Rojas, P. Avila et al., "Insulin reverses Dglucose-increased nitric oxide and reactive oxygen species generation in human umbilical vein endothelial cells," PLoS ONE, vol. 10, no. 4, Article ID e0122398, 2015.

[19] E. Ros, M. A. Martínez-González, R. Estruch et al., "Mediterranean diet and cardiovascular health: teachings of the PREDIMED study," Advances in Nutrition, vol. 5, no. 3, pp. S330-S336, 2014.

[20] S. S. Martin, M. J. Blaha, R. Blankstein et al., "Dyslipidemia, coronary artery calcium, and incident atherosclerotic cardiovascular disease: implications for statin therapy from the multiethnic study of atherosclerosis," Circulation, vol. 129, no. 1, pp. 77-86, 2014.

[21] N. J. Stone, J. G. Robinson, A. H. Lichtenstein et al., “Treatment of blood cholesterol to reduce atherosclerotic cardiovascular disease risk in adults: synopsis of the 2013 American college of cardiology/American heart association cholesterol guideline," Annals of Internal Medicine, vol. 160, no. 5, pp. 339-343, 2014.
[22] M. E. Baardman, W. S. Kerstjens-Frederikse, R. M. F. Berger, M. K. Bakker, R. M. W. Hofstra, and T. Plösch, "The role of maternal-fetal cholesterol transport in early fetal life: current insights," Biology of Reproduction, vol. 88, no. 1, pp. 1-9, 2013.

[23] World Health Organization, Global Status Report on NonCommunicable Diseases, vol. 1, World Health Organization, Geneva, Switzerland, 2010.

[24] U. Martin, C. Davies, S. Hayavi, A. Hartland, and F. Dunne, "Is normal pregnancy atherogenic?” Clinical Science, vol. 96, no. 4, pp. 421-425, 1999.

[25] E. Herrera, "Lipid metabolism in pregnancy and its consequences in the fetus and newborn," Endocrine, vol. 19, no. 1, pp. 43-55, 2002.

[26] A. Basaran, "Pregnancy-induced hyperlipoproteinemia: review of the literature," Reproductive Sciences, vol. 16, no. 5, pp. 431437, 2009.

[27] A. Liguori, F. P. D’Armiento, A. Palagiano et al., "Effect of gestational hypercholesterolaemia on omental vasoreactivity, placental enzyme activity and transplacental passage of normal and oxidised fatty acids," BJOG, vol. 114, no. 12, pp. 1547-1556, 2007.

[28] W. Palinski, "Maternal-fetal cholesterol transport in the placenta: good, bad, and target for modulation," Circulation Research, vol. 104, no. 5, pp. 569-571, 2009.

[29] M. Ethier-Chiasson, A. Duchesne, J.-C. Forest et al., "Influence of maternal lipid profile on placental protein expression of LDLr and SR-BI," Biochemical and Biophysical Research Communications, vol. 359, no. 1, pp. 8-14, 2007.

[30] J. K. Bendall, G. Douglas, E. McNeill, K. M. Channon, and M. J. Crabtree, "Tetrahydrobiopterin in cardiovascular health and disease," Antioxidants and Redox Signaling, vol. 20, no. 18, pp. 3040-3077, 2014.

[31] C. Marseille-Tremblay, M. Ethier-Chiasson, J.-C. Forest et al., "Impact of maternal circulating cholesterol and gestational diabetes mellitus on lipid metabolism in human term placenta," Molecular Reproduction and Development, vol. 75, no. 6, pp. 1054-1062, 2008.

[32] S. H. Badruddin, R. Lalani, M. Khurshid, A. Molla, R. Qureshi, and M. A. Khan, "Serum cholesterol in neonates and their mothers. A pilot study," Journal of the Pakistan Medical Association, vol. 40, no. 5, pp. 108-109, 1990.

[33] L. Sobrevia, R. Salsoso, T. Sáez, C. Sanhueza, F. Pardo, and A. Leiva, "Insulin therapy and fetoplacental vascular function in gestational diabetes mellitus," Experimental Physiology, vol. 100, no. 3, pp. 231-238, 2015.

[34] D. Marzioni, L. Tamagnone, L. Capparuccia et al., "Restricted innervation of uterus and placenta during pregnancy: evidence for a role of the repelling signal semaphorin 3A," Developmental Dynamics, vol. 231, no. 4, pp. 839-848, 2004.

[35] L. Sobrevia, F. Abarzúa, J. K. Nien et al., "Review: differential placental macrovascular and microvascular endothelial dysfunction in gestational diabetes," Placenta, vol. 32, supplement 2, pp. S159-S164, 2011.

[36] J. Deanfield, A. Donald, C. Ferri et al., "Endothelial function and dysfunction. Part I: methodological issues for assessment in the different vascular beds: A statement by the working group on endothelin and endothelial factors of the European society of hypertension," Journal of Hypertension, vol. 23, no. 1, pp. 7-17, 2005.

[37] A. Vahratian, V. K. Misra, S. Trudeau, and D. P. Misra, "Prepregnancy body mass index and gestational age-dependent changes 
in lipid levels during pregnancy," Obstetrics and Gynecology, vol. 116, no. 1, pp. 107-113, 2010.

[38] I. C. R. dos Santos-Weiss, R. R. Réa, C. M. T. Fadel-Picheth et al., "The plasma logarithm of the triglyceride/HDL-cholesterol ratio is a predictor of low risk gestational diabetes in early pregnancy," Clinica Chimica Acta, vol. 418, pp. 1-4, 2013.

[39] L. Ywaskewycz, G. Bonneau, M. Castillo, D. López, and R. Pedrozo, "Perfil lipídico por trimestre de gestación en una población de mujeres adultas," Revista Chilena de Obstetricia y Ginecología, vol. 75, pp. 227-233, 2010.

[40] J. C. Mazurkiewicz, G. F. Watts, F. G. Warburton, B. M. Slavin, C. Lowy, and E. Koukkou, "Serum lipids, lipoproteins and apolipoproteins in pregnant non-diabetic patients," Journal of Clinical Pathology, vol. 47, no. 8, pp. 728-731, 1994.

[41] V. Toescu, S. L. Nuttall, U. Martin et al., "Changes in plasma lipids and markers of oxidative stress in normal pregnancy and pregnancies complicated by diabetes," Clinical Science, vol. 106, no. 1, pp. 93-98, 2004.

[42] Ä. Bartels, N. Egan, D. I. Broadhurst et al., "Maternal serum cholesterol levels are elevated from the 1st trimester of pregnancy: a cross-sectional study," Journal of Obstetrics and Gynaecology, vol. 32, no. 8, pp. 747-752, 2012.

[43] P. Brizzi, G. Tonolo, F. Esposito et al., "Lipoprotein metabolism during normal pregnancy," American Journal of Obstetrics and Gynecology, vol. 181, no. 2, pp. 430-434, 1999.

[44] L. Fåhraeus, U. Larsson-Cohn, and L. Wallentin, "Plasma lipoproteins including high density lipoprotein subfractions during normal pregnancy," Obstetrics and Gynecology, vol. 66, no. 4, pp. 468-472, 1985.

[45] I. Sánchez-Vera, B. Bonet, M. Viana et al., "Changes in plasma lipids and increased low-density lipoprotein susceptibility to oxidation in pregnancies complicated by gestational diabetes: consequences of obesity," Metabolism: Clinical and Experimental, vol. 56, no. 11, pp. 1527-1533, 2007.

[46] J. J. Alvarez, A. Montelongo, A. Iglesias, M. A. Lasunción, and E. Herrera, "Longitudinal study on lipoprotein profile, high density lipoprotein subclass, and postheparin lipases during gestation in women," Journal of Lipid Research, vol. 37, no. 2, pp. 299-308, 1996.

[47] A. Zeljkovic, J. Vekic, S. Spasic et al., "Changes in LDL and HDL subclasses in normal pregnancy and associations with birth weight, birth length and head circumference," Maternal and Child Health Journal, vol. 17, no. 3, pp. 556-565, 2013.

[48] T. Emet, I. Üstüner, S. G. Güven et al., "Plasma lipids and lipoproteins during pregnancy and related pregnancy outcomes," Archives of Gynecology and Obstetrics, vol. 288, no. 1, pp. 49-55, 2013.

[49] A. Wiznitzer, A. Mayer, V. Novack et al., "Association of lipid levels during gestation with preeclampsia and gestational diabetes mellitus: a population-based study," American Journal of Obstetrics and Gynecology, vol. 201, no. 5, pp. 482-e8, 2009.

[50] E. E. Neboh, J. K. Emeh, U. U. Aniebue, E. J. Ikekpeazu, I. C. Maduka, and F. O. Ezeugwu, "Relationship between lipid and lipoprotein metabolism in trimesters of pregnancy in Nigerian women: is pregnancy a risk factor?" Journal of Natural Science, Biology and Medicine, vol. 3, no. 1, pp. 32-37, 2012.

[51] Y. Fukuda, H. Teragawa, K. Matsuda, T. Yamagata, H. Matsuura, and K. Chayama, "Tetrahydrobiopterin improves coronary endothelial function, but does not prevent coronary spasm in patients with vasospastic angina," Circulation Journal, vol. 66, no. 1, pp. 58-62, 2002.
[52] F. Cosentino, D. Hürlimann, C. Delli Gatti et al., "Chronic treatment with tetrahydrobiopterin reverses endothelial dysfunction and oxidative stress in hypercholesterolaemia," Heart, vol. 94, no. 4, pp. 487-492, 2008.

[53] C. A. Wyss, P. Koepfli, M. Namdar et al., "Tetrahydrobiopterin restores impaired coronary microvascular dysfunction in hypercholesterolaemia," European Journal of Nuclear Medicine and Molecular Imaging, vol. 32, no. 1, pp. 84-91, 2005.

[54] L. M. Alexander, J. L. Kutz, and W. L. Kenney, "Tetrahydrobiopterin increases NO-dependent vasodilation in hypercholesterolemic human skin through eNOS-coupling mechanisms," The American Journal of Physiology-Regulatory Integrative and Comparative Physiology, vol. 304, no. 2, pp. R164-R169, 2013.

[55] L. A. Holowatz and W. L. Kenney, "Acute localized administration of tetrahydrobiopterin and chronic systemic atorvastatin treatment restore cutaneous microvascular function in hypercholesterolaemic humans," The Journal of Physiology, vol. 589, no. 19, pp. 4787-4797, 2011.

[56] M. C. Bowers, L. A. Hargrove, K. A. Kelly, G. Wu, and C. J. Meininger, "Tetrahydrobiopterin attenuates superoxideinduced reduction in nitric oxide," Frontiers in Bioscience, vol. 3, no. 4, pp. 1263-1272, 2011.

[57] Q.-W. Xie and C. Nathan, "The high-output nitric oxide pathway: role and regulation," Journal of Leukocyte Biology, vol. 56, no. 5, pp. 576-582, 1994.

[58] I. Fleming and R. Busse, "Molecular mechanisms involved in the regulation of the endothelial nitric oxide synthase," The American Journal of Physiology-Regulatory Integrative and Comparative Physiology, vol. 284, no. 1, pp. 1-12, 2003.

[59] I. Fleming, "Molecular mechanisms underlying the activation of eNOS," Pflugers Archiv European Journal of Physiology, vol. 459, no. 6, pp. 793-806, 2010.

[60] S. Dimmeler, I. Fleming, B. Fisslthaler, C. Hermann, R. Busse, and A. M. Zeiher, "Activation of nitric oxide synthase in endothelial cells by Akt- dependent phosphorylation," Nature, vol. 399, no. 6736, pp. 601-605, 1999.

[61] I. Fleming, B. Fisslthaler, S. Dimmeler, B. E. Kemp, and R. Busse, "Phosphorylation of $\mathrm{Thr}^{495}$ regulates $\mathrm{Ca}^{2+} /$ calmodulindependent endothelial nitric oxide synthase activity," Circulation Research, vol. 88, no. 11, pp. e68-e75, 2001.

[62] J. K. Liao, W. S. Shin, W. Y. Lee, and S. L. Clark, "Oxidized low-density lipoprotein decreases the expression of endothelial nitric oxide synthase," The Journal of Biological Chemistry, vol. 270, no. 1, pp. 319-324, 1995.

[63] F. Vidal, C. Colomé, J. Martínez-González, and L. Badimon, "Atherogenic concentrations of native low-density lipoproteins down-regulate nitric-oxide-synthase mRNA and protein levels in endothelial cells," European Journal of Biochemistry, vol. 252, no. 3, pp. 378-384, 1998.

[64] A. Jiménez, M. M. Arriero, A. López-Blaya et al., "Regulation of endothelial nitric oxide synthase expression in the vascular wall and in mononuclear cells from hypercholesterolemic rabbits," Circulation, vol. 104, no. 15, pp. 1822-1830, 2001.

[65] D. Xie, S. I. Odronic, F. Wu, A. M. Pippen, C. F. Donatucci, and B. H. Annex, "A mouse model of hypercholesterolemia-induced erectile dysfunction," The Journal of Sexual Medicine, vol. 4, no. 4, pp. 898-907, 2007.

[66] M. P. Robich, R. M. Osipov, R. Nezafat et al., "Resveratrol improves myocardial perfusion in a swine model of hypercholesterolemia and chronic myocardial ischemia," Circulation, vol. 122, no. 11, pp. S142-S149, 2010. 
[67] C. Mineo, I. S. Yuhanna, M. J. Quon, and P. W. Shaul, "High density lipoprotein-induced endothelial nitric-oxide synthase activation is mediated by Akt and MAP kinases," Journal of Biological Chemistry, vol. 278, no. 11, pp. 9142-9149, 2003.

[68] S. Ryoo, A. Bhunia, F. Chang, A. Shoukas, D. E. Berkowitz, and L. H. Romer, "OxLDL-dependent activation of arginase II is dependent on the LOX-1 receptor and downstream RhoA signaling," Atherosclerosis, vol. 214, no. 2, pp. 279-287, 2011.

[69] S. Ryoo, C. A. Lemmon, K. G. Soucy et al., "Oxidized lowdensity lipoprotein-dependent endothelial arginase II activation contributes to impaired nitric oxide signaling," Circulation Research, vol. 99, no. 9, pp. 951-960, 2006.

[70] S. Ryoo, G. Gupta, A. Benjo et al., "Endothelial arginase II: a novel target for the treatment of atherosclerosis," Circulation Research, vol. 102, no. 8, pp. 923-932, 2008.

[71] L. A. Holowatz and W. L. Kenney, "Up-regulation of arginase activity contributes to attenuated reflex cutaneous vasodilatation in hypertensive humans," Journal of Physiology, vol. 581, no. 2, pp. 863-872, 2007.

[72] L. A. Holowatz, L. Santhanam, A. Webb, D. E. Berkowitz, and W. L. Kenney, "Oral atorvastatin therapy restores cutaneous microvascular function by decreasing arginase activity in hypercholesterolaemic humans," Journal of Physiology, vol. 589, no. 8, pp. 2093-2103, 2011.

[73] B. Thöny, G. Auerbach, and N. Blau, "Tetrahydrobiopterin biosynthesis, regeneration and functions," Biochemical Journal, vol. 347, no. 1, pp. 1-16, 2000.

[74] J. Vásquez-Vivar, B. Kalyanaraman, P. Martásek et al., "Superoxide generation by endothelial nitric oxide synthase: the influence of cofactors," Proceedings of the National Academy of Sciences of the United States of America, vol. 95, no. 16, pp. 92209225, 1998.

[75] F. Cosentino, K. Hishikawa, Z. S. Katusic, and T. F. Lüscher, "High glucose increases nitric oxide synthase expression and superoxide anion generation in human aortic endothelial cells," Circulation, vol. 96, no. 1, pp. 25-28, 1997.

[76] W. Maier, F. Cosentino, R. B. Lütolf et al., “Tetrahydrobiopterin improves endothelial function in patients with coronary artery disease," Journal of Cardiovascular Pharmacology, vol. 35, no. 2, pp. 173-178, 2000.

[77] U. Landmesser, S. Dikalov, S. R. Price et al., "Oxidation of tetrahydrobiopterin leads to uncoupling of endothelial cell nitric oxide synthase in hypertension," Journal of Clinical Investigation, vol. 111, no. 8, pp. 1201-1209, 2003.

[78] M. A. Creager, J. P. Cooke, M. E. Mendelsohn et al., "Impaired vasodilation of forearm resistance vessels in hypercholesterolemic humans," Journal of Clinical Investigation, vol. 86, no. 1, pp. 228-234, 1990.

[79] C. Napoli and L. J. Ignarro, "Nitric oxide and pathogenic mechanisms involved in the development of vascular diseases," Archives of Pharmacal Research, vol. 32, no. 8, pp. 1103-1108, 2009.

[80] Q. Wang, M. Yang, H. Xu, and J. Yu, “Tetrahydrobiopterin improves endothelial function in cardiovascular disease: a systematic review," Evidence-Based Complementary and Alternative Medicine, vol. 2014, Article ID 850312, 7 pages, 2014.

[81] J. B. Laursen, M. Somers, S. Kurz et al., "Endothelial regulation of vasomotion in apoE-deficient mice: implications for interactions between peroxynitrite and tetrahydrobiopterin," Circulation, vol. 103, no. 9, pp. 1282-1288, 2001.

[82] M. Ozaki, S. Kawashima, T. Yamashita et al., "Overexpression of endothelial nitric oxide synthase accelerates atherosclerotic lesion formation in apoE-deficient mice," The Journal of Clinical Investigation, vol. 110, no. 3, pp. 331-340, 2002.

[83] N. J. Alp and K. M. Channon, "Regulation of endothelial nitric oxide synthase by tetrahydrobiopterin in vascular disease," Arteriosclerosis, Thrombosis, and Vascular Biology, vol. 24, no. 3, pp. 413-420, 2004.

[84] J. Dulak, M. Polus, I. Guevara, A. Polus, J. Hartwich, and A. Dembińska-Kieć, "Regulation of inducible nitric oxide synthase (iNOS) and GTP cyclohydrolase I (GTP-CH I) gene expression by OX-LDL in rat vascular smooth muscle cells," Journal of Physiology and Pharmacology, vol. 48, no. 4, pp. 689-697, 1997.

[85] J. Dulak, M. Polus, I. Guevara et al., "Oxidized low density lipoprotein inhibits inducible nitric oxide synthase, GTP cyclohydrolase I and transforming growth factor $\beta$ gene expression in rat macrophages," Journal of Physiology and Pharmacology, vol. 50, no. 3, pp. 429-441, 1999.

[86] S. Cai, J. Khoo, and K. M. Channon, "Augmented BH4 by gene transfer restores nitric oxide synthase function in hyperglycemic human endothelial cells," Cardiovascular Research, vol. 65, no. 4, pp. 823-831, 2005.

[87] C. Aoki, A. Nakano, S. Tanaka et al., "Fluvastatin upregulates endothelial nitric oxide synthase activity via enhancement of its phosphorylation and expression and via an increase in tetrahydrobiopterin in vascular endothelial cells," International Journal of Cardiology, vol. 156, no. 1, pp. 55-61, 2012.

[88] A. Leiva, B. Fuenzalida, B. Sobrevia, F. Pardo, and L. Sobrevia, "Maternal supraphysiological hypercholesterolemia leads to reduced nitric oxide synthase activity associated with reduced levels of tetrahydrobiopterin in huvec," Atherosclerosis, vol. 235, no. 2, p. e37, 2014. 


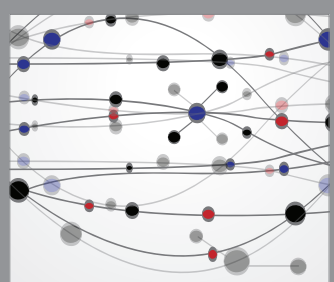

The Scientific World Journal
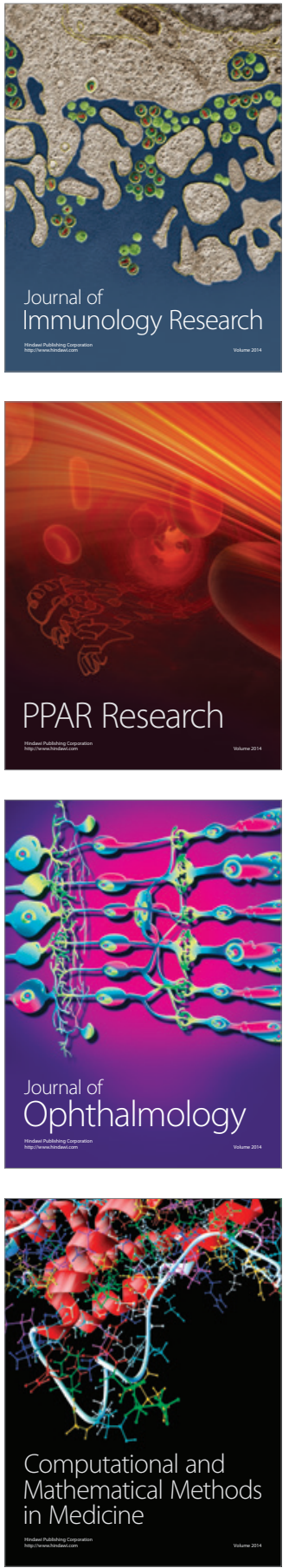

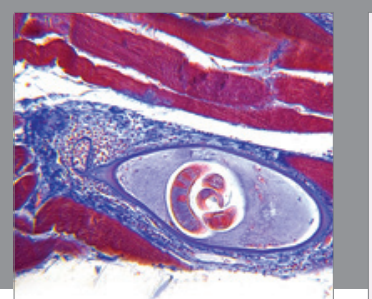

Gastroenterology Research and Practice

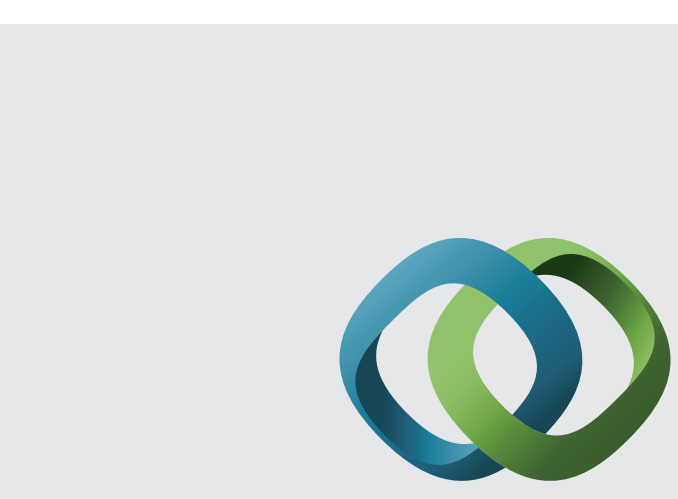

\section{Hindawi}

Submit your manuscripts at

http://www.hindawi.com
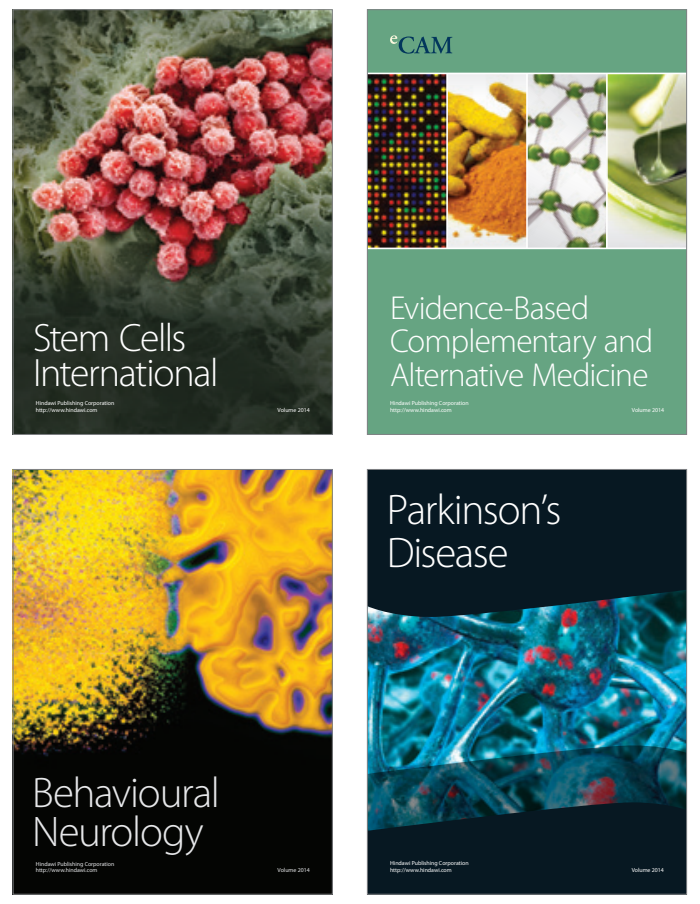
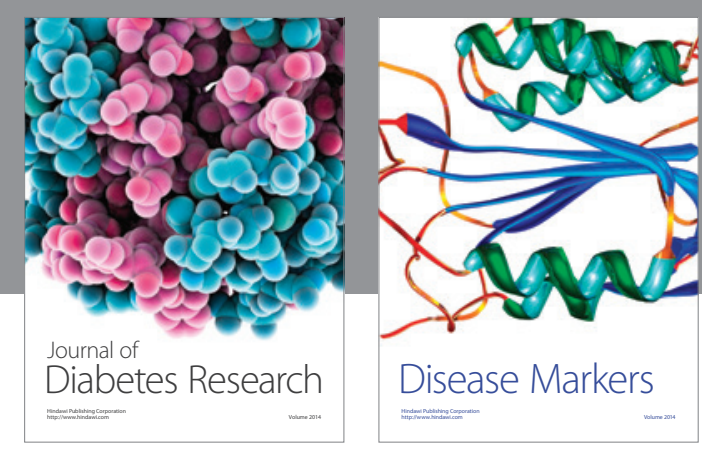

Disease Markers
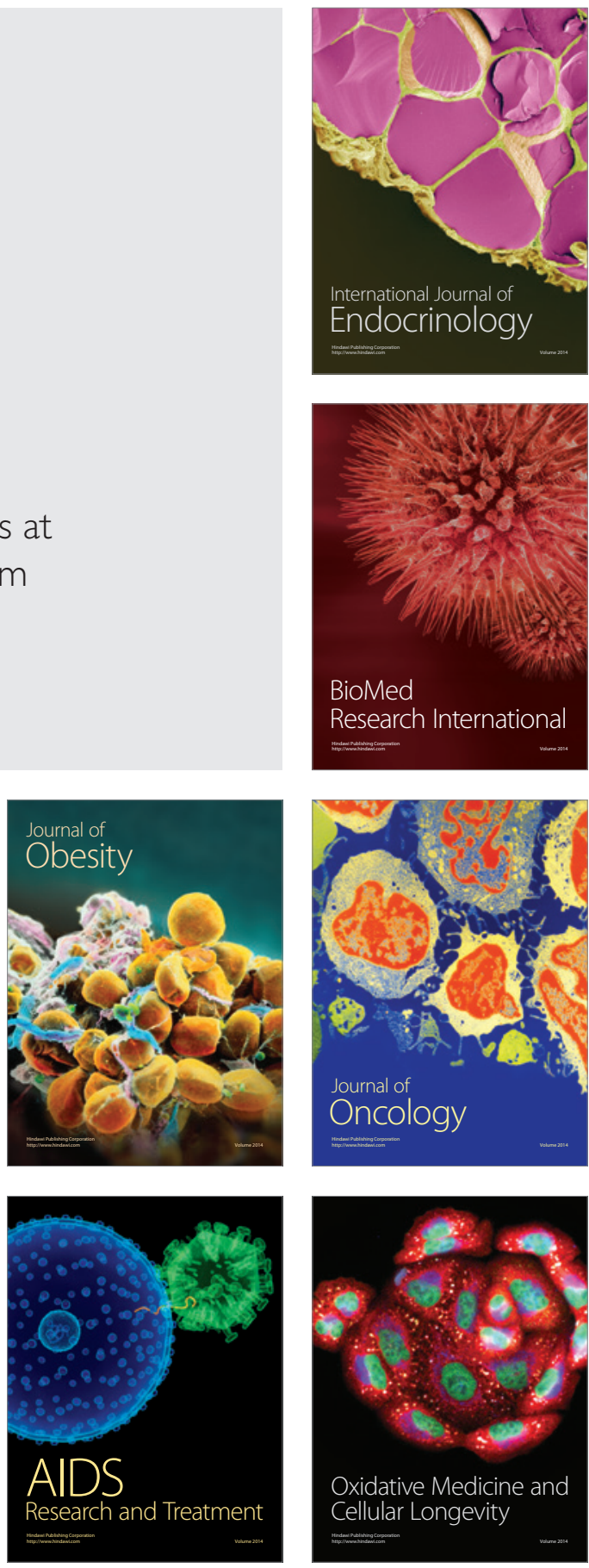